\title{
ALTERATION IN SERUM ZINC AND COPPER CONCENTRATIONS AND EFFECT OF ORAL THERAPEUTIC SUPPLEMENTATION OF ZINC ON TRANSFUSION DEPENDANT BETA THALASSEMIA MAJOR PATIENTS
}

\author{
Ghone RA ${ }^{1}$, Ghodake $\mathrm{SS}^{2}$, Bhagat $\mathrm{SS}^{3}$, Karnik $\mathrm{AC}^{3}$ \\ ${ }^{1}$ Associate Professor, ${ }^{4}$ Professor \& HOD, Department of Biochemistry, ACPM Medical College, Dhule, \\ ${ }^{2}$ Prof \& Head, ${ }^{3}$ Assistant Professor, Department of Biochemistry, \\ DVVPF's Medical College, Ahmednagar, Maharashtra, India.
}

\begin{abstract}
Zinc is one of the essential micronutrients in human and act as a cofactor for more than 300 enzymes and plays an essential role in human growth and development. It has been observed that there was low serum zinc and elevated copper level in $\beta$-thalassemia major compared with normal. Zinc deficiency is considered one of the main factors contributing to growth, cardiovascular diseases, and puberty disorders in $\beta$-thalassemic patients. Aim: The goal of the study was to scrutinize the impact of serum zinc and copper concentration in patients with beta-thalassemia major and also to observe the effect of zinc supplementation on transfusion dependent beta-thalassemia patients for six months. Method: 52 beta-thalassemia major patients were studied before and after supplementation of zinc for six months, and status was compared with 52 age and sex-matched healthy normal. Serum zinc and copper concentration were measured by atomic absorption spectrophotometry (AAS) method. Result: There was a significant depleted activity of serum zinc level $(p<0.001)$, and the copper level was increased significantly $(p<0.001)$ in patients when compared with normal. After six months of supplementation of zinc, there was a significantly enhanced zinc concentration $(p<0.001)$, and copper was marginally increased $(p>0.05)$ when compared with normal and baselines. Conclusion: Beta Thalassemia major children are on numerous blood transfusions all the way through their life. Due to this thalassemic children are at risk of secondary iron burden. This further leads to the enhanced oxidative stress. One of the way to may overcome this situation to supply regular zinc supplementation along with treatment, which may be helpful to manage the situation.
\end{abstract}

Keywords: Beta thalassemia major; Serum zinc; Serum copper; Oxidative stress.

\section{INTRODUCTION}

Beta thalassemia major is the most widespread autosomal recessive hereditary disease [1]. This disease is characterized by the decreased synthesis of beta polypeptide chains [2]. Thalassemia is usually associated with many complications such as atherosclerosis, severe infections, pallor, hepatosplenomegaly, gall stones, and some bone deformities that alter facial structures. The overall effect of all these characteristics leads to pathological changes like ineffective erythropoiesis, jaundice, hemolysis, which further lead s severe anemia [3,4].

Beta thalassemia is treated with multiple blood transfusions, which mainly leads to the iron overload and generation of oxidative stress [4]. Today, different studies indicate that the high levels of oxygen together with hemoglobin containing iron attacks on the nonsaturated fatty acids and $\mathrm{RBCs}$, results in excess production of $(\mathrm{OH})$, singlet oxygen, and reactive oxygen species (ROS) in the red blood cells of thalassemia patients, this alters the redox status of these patients and intensification of oxidative stress with gross depletion of antioxidant nutrients [4,5].

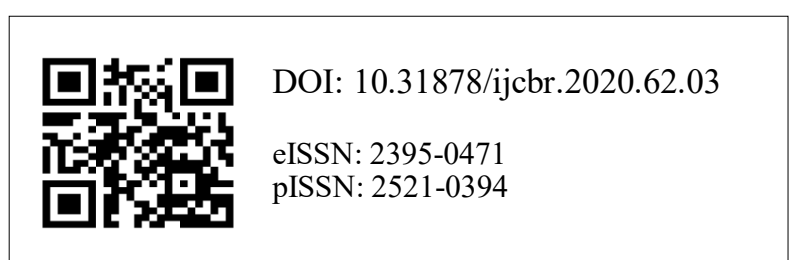

In India, every year, more than 10,000 children are born with thalassemia major. About 190 million throughout the world having genetic mutations associated with different hemoglobinopathies, and more than 90 million of them carry defective genes leading to thalassemia [68].

The trace elements and minerals play a crucial role in the body to perform overall functions properly [9].

Zinc has a vital role in red blood cell survival, and zinc deficiency leads to membrane fragility ${ }^{10}$. Copper is the measure component of hemoglobin, and it is the central component of the antioxidant superoxide dismutase molecule. It also helps in the formation of a protein called ceruloplasmin, which protects the cells from free radical injury [9]. Zinc was a deficient and enhanced copper concentration in major thalassemia patients. The zinc level mainly decreased due to attributable to iron chelation, dietary deficiency, increased urinary zinc excretion, chronic infections, and ongoing hemolysis. The copper is increased mainly due to a compensatory mechanism and due to hemochromatosis $[9,10]$.

Supplementation with zinc orally $(50 \mathrm{mg} /$ day) in betathalassemia major patients leads to enhance trace elements concentration and boosts the overall immune response ${ }^{11}$. Due to regular blood transfusion, there was enhanced oxidative stress due to secondary iron overload along with depleted levels of trace elements in

Correspondence: : Dr. S. S. Ghodake, Prof \& Head, Department of Biochemistry, DVVPF's Medical College, Ahmednagar, Maharashtra, India. Email: ghodke3@gmail.com 
thalassemia major. Due to additional supplementation of zinc decreases the hemolysis, maintains cell integrity, and inhibit the oxidative stress $[11,12]$.

\section{MATERIAL AND METHODOLOGY}

Study design: The study is a randomized, singleblinded placebo-controlled prospective study.

Ethics approval: The Institutional Ethical Committee clearance was obtained from the above mentioned institutes, and the utmost care was taken during study procedure according to the Declaration of Helsinki 1975.

Study locus: This research was conducted in the Department of Biochemistry PDVVPF's Medical College, Ahmednagar, Maharashtra.

Study time frame: The duration of the study was 15 months.

Sample size: The study has been performed on a total of 104 subjects

Inclusion criteria: Which included 52 age and sexmatched (28 males and 24 females) healthy normal and 52 (17 males and 35 females) $\beta$ - thalassemia children, which were previously diagnosed by High-Performance Liquid Chromatography (HPLC) and electrophoretic patterns. All thalassemic patients receive an oral dose of deferiprone as an iron chelator in a regular dose. All patients were under the strict supervision of medical professionals during this period. The patients were blood transfusion-dependent, aged between 4-10 years. The average hemoglobin concentration ranged between $3-7.7 \mathrm{gm} / \mathrm{dl}$.

Exclusion criteria: All the patients having a history of hypertension, thyroid dysfunction, diabetes mellitus, cardiovascular diseases, which induce oxidative stress, were excluded from the study.

Grouping: Group 1 Healthy volunteers ( Control), group 2: beta-thalassemia major children

\section{Methodology}

A total of $3 \mathrm{ml}$ blood was withdrawn aseptically from the antecubital vein from each subject in plain blub. The samples were centrifuged at $3000 \mathrm{rpm}$ for $10 \mathrm{~min}$ to separate serum. The separated serum was collected in a polythene tube with cork and stored at $-20^{\circ} \mathrm{C}$. The serum with no sign of hemolysis was used for the analysis of all the parameters. Serum zinc and copper was assessed by atomic absorption spectrophotometry [13].The assessment of the above parameters from patient groups was conducted before and after 6 months of the zinc supplementation $50 \mathrm{mg}$ /day orally O.D.

Statistical analysis: The statistical analysis was carried out by using the SPSS (Statistical Package for Social Sciences) software, version 16.0 for Windows. The Student ' $Z$ ' test was applied to assess the difference between means of intervention and normal and pre and post-intervention data. The results were expressed in mean $\pm S D ; p$ values $(p<0.001)$ were considered as highly significant, and $p$ values $(p>0.05)$ were considered as non-significant.

\section{RESULTS}

Table-1 shows significantly decreased $(p<0.001)$ levels of serum zinc and the level of copper was increased significantly $(p<0.001)$ in patients with beta-thalassemia major when compared with healthy normal before supplementation. After six months of zinc supplementation to patients group along with regular treatment, it was observed that a significant increase in the levels of zinc $(p<0.001)$ and a non-significant increase in serum copper concentration $(p>0.05)$ was seen when compared with baseline results.

Table 1: Serum zinc and copper concentrations in normal and beta-thalassemia major children before and after zinc supplementation

\begin{tabular}{|c|c|c|c|}
\hline \multirow{2}{*}{$\begin{array}{l}\text { Parameters } \\
(\mu \mathrm{g} / \mathrm{dl})\end{array}$} & \multirow{2}{*}{$\begin{array}{l}\text { Normal } \\
(n=52)\end{array}$} & \multicolumn{2}{|c|}{$\begin{array}{l}\text { Supplementation of zinc } \\
(\mathrm{n}=52)\end{array}$} \\
\hline & & Before & After \\
\hline Serum zinc & $97.34 \pm 81.19$ & $62.87 \pm 07.1 * *$ & $75.3 \pm 05.8^{\$ \$}$ \\
\hline Serum copper & $138.58 \pm 14.9$ & $138.8 \pm 10.5^{* *}$ & $142.2 \pm 10.3$ \\
\hline
\end{tabular}

Values are expressed in mean with standard deviation (mean \pm SD). Statistical comparison was done between normal, group II before and after by applying student ' $Z$ ' test for individual comparison. $* * \mathrm{P}<0.001$ - considered as highly significant. **comparison between group 1 and Group II before supplementation of zinc, ${ }^{\$}$ Comparison between group before and after supplementation of Zinc

\section{DISCUSSION}

Zinc is an essential element for growth and immunity ${ }^{10}$. Due to regular blood transfusion, there was a continuous iron overload, which leads to enhanced oxidative stress and diminished antioxidant concentrations [14]. Our findings suggest that iron overload may be the most substantial negative influence on circulating micronutrients such as zinc, vitamin $\mathrm{E}, \mathrm{C}$, and overall antioxidant status [15].

Our findings confirm with Mohammadreza Rashidi et al. that they found the significantly lowered activity of serum zinc in patients with beta-thalassemia major. With research, they proved that supplementation of oral zinc with vitamin $E$ increases the serum zinc and vitamin $E$ concentration [16]. This helps to reduce the hemolytic rate and thereby decreases the urinary excretion of zinc in major thalassemia patients.

Excess iron accumulation leads to growth impairment, endocrinopathy, hypogonadism, etc. in beta-thalassemia patients. Various reports emphasize the role of zinc and copper associated with these clinical problems. Zinc is the essential nutrient and is considered to be an essential mineral preceded by iron.

Abolfazl et al. described depletion in zinc activity and elevated copper level in patients with $\beta$-thalassemia major. He further explained that the cause of zinc deficiency was due to insufficient dietary zinc intake, and hence he recommended additional zinc supplementation for thalassemia patients [17].

Our findings sustained with the results made by Ghone RA et al. that depleted serum zinc in $\beta$-thalassemia major had been attributed to enhanced levels of zinc, which may 
be due to cirrhotic changes owing to hemosiderosis or it may be an increased rate of glomerular filtration of zinc as seen in chronic hemolysis. Increased copper activity may be due to antagonistic effects of the zinc, as a zinc deficiency in $\beta$-thalassemia major patients could much promote popper absorption via GIT [18].

Other researchers also provided similar reports. They attributed that the cause of hypozincemia in thalassemia major is hyper-zincuria, which is resulted in hemolysis of RBCs. Some studies show that increased copper level may be due to hemochromatosis, which is the principal complication in thalassemia major $[19,20]$.

\section{CONCLUSION}

The core of the present study lies in the fact that zinc deficiency and tissue damage due to iron overloadinduced oxidative stress. Biologically zinc interacts with iron and inhibits oxidation-reduction reactions. The $\beta$ thalassemia major patients are under the heavy risk of cardiovascular decreases due to increased low-density lipoprotein levels and deposition of free iron in the heart. The daily supplementation of $220 \mathrm{mg}$ zinc sulfate capsule contented $50 \mathrm{mg}$ elemental zinc for six months significantly improves the serum zinc level, and delays the cardiovascular disease risk in $\beta$-thalassemia major patients.

Acknowledgement: The authors genuinely acknowledges all the parents of thalassemic patients, who allow collecting the blood sample.

Conflict of interest : Nil

Source of funding : Nil

\section{REFERENCES}

[1] Asmaa Nafady, Sanaa Shaker Ali, Hosney Mohammed, Ahmed EI Masry, Khaled Abdel Baseer et al. Oxidative stress in pediatric patients with $\beta$ - thalassemia major. Egyptian Journal of Haematology 2017; 42 (3): 123-7

[2] Mahmood Asif, Zahid Mansoor, UzmaS haheen, Amama Kawal. Effect of multiple blood transfusions on hormonal profile in thalassemia children. Rawal Medical Journal 2014;39(3): 2659

[3] Hasan F AL-Azzawie, Noor A Salman. Association of vitamin profile with oxidant/ Antioxidant status in Iraqi $\beta$ - thalassemic major children. J. Pharmacology and Clinical Research 2017;4(4): 1-5

[4] Mamta Choudhary, Raj Kumar Vyas, Anil Lahoti. Correlation of oxidative stress with serum antioxidant enzymes level in thalassemia in a tertiary level hospital of western Rajasthan. International Journal of Biotechnology and Biochemistry, 2017;13(2):155-65

[5] Livrea MA, Tesoriere L, Pintaudi AM et. al. Oxidative stress and Antioxidant status in beta thalassemia major: Iron overload and depletion of lipid soluble antioxidants. Blood 1996; 88(9):3608 $-14$

[6] Widad NM, Al-Naama L, Meaad. Trace element in patients with beta thalassemia major. Haem.2003;6(3):376-83
[7] Das N, Chowdhury TD, Chattopadhyay A, Datta. Attenuation of oxidation stress- induced changes in thalassemic erythrocytes by Vitamin E. Pol J Pharmocol. 2004;56: 85-96

[8] Ambekar SS, Phadke MA, Balpande DN, Mokashi GD, Khedkar VA, et al. The prevalence and Heterogeneity of Beta Thalassemia Mutation in The Western Maharashtra Population: A hospitalbased study. IJHG 2001;1(3):219-23

[9] Shazia Q,Mohammad ZH,Taibur Rahman, Hossain Uddin Shekhar. Correlation of Oxidative Stress with Serum Trace Element Levels and Antioxidant Enzyme Status in Beta Thalassemia Major Patients: A Review of the Literature. Hindawi Publishing Corporation Anemia. 2012;1:1-7

[10] Hidhab Jawad Muhssen, Qasim M. Hashim Al Moussawi, Ashwaq Ali Hussein, Ali Hadi Mahdi. Assessment of Serum Zinc Level in Children with Thalassemia Major Receiving Oral Chelation and Their Sibling in AL-Najaf City. Int Journal of Science and Research 2016;7(1):746-51

[11] Attakorn Palasuwan, Methee Sriprapun, Winai Dahlan, Rataya Luechapudiporn et al. Antioxidant protection in hemoglobin $\mathrm{E}$ trait subjects after vitamin E supplementation. Southeast Asian J Trop Med Public Health 2008;39(1):82-9

[12] Jilani T, Iqbal M. Does vitamin E have a role in the treatment and prevention of anemia?. Pakistan J. of Pharmaceutical Sci. 2011;24(2): 237-42

[13] Varley H. Atomic Absorption Spectroscopy. In: Practical clinical biochemistry. Heineman professional publishing1998; $6^{\text {th }}$ Ed:p $167-74$

[14] Sonali S Bhagat, Purnima Dey Sarkar, Adinath N Suryakar, Ghone RA et al.Special Effects of Oral Therapeutic Supplementation of Antioxidants on Attenuation of Iron Overload in Homozygous Beta Thalassemia. International Journal of Health Sciences \& Research, 2012;37(2):36-8

[15] Elijah KG, Sushrita Neogi, AshutoshLal, Annie Higa. nutritional deficiencies are common in patients with transfusion dependant thalassemia and associated with iron overload. $\mathrm{J}$ of Food and Nutrition research 2018; 6(10):674-81

[16] Mohammadreza Rashidi, Maryam A, Maryam R, Seyed RA. Effects of vitamin $E$ and zinc supplementation on antioxidants in beta thalassemia major patients. Iran J Pediatr 2011;21 (1):8-14

[17] Abolfazl M, Parviz A, Ali- Asghar P. Zinc and copper status in children with beta - thalassemia major. Iran J Pediatr 2010;20(3):297-302

[18] Ghone RA, Kumbar KM, Suryakar AN, Katkam RV, Joshi NG. Oxidative stress and disturbance in antioxidant balance in beta thalassemia major. Indian Journal of Clinical Biochemistry 2008;23 (4):337-40.

[19] Foroogh SH, Maryam A, Seyed MH. Serum and urine level of zinc in patients with minor beta thalassemia in Ali-asghar Hospital during the years 2005-2006. Iranian J of Pathology 2007;2 (2):54

[20] Anuja Adarsh, Asha Khubchandani, Disha Gajjar. Alteration in trace elements in thalassemia major patients after chelation therapy. Int J Med SciEduc 2019; 6(1):63-5 